\title{
A CRIMINOLOGIA MIDIÁTICA COMO UM ARAUTO DA GUERRA ÀS DROGAS
}

\author{
Filipe de Sousa Alcântara
}

Graduando no curso de Direito na Universidade Federal da Bahia (UFBA)

\begin{abstract}
RESUMO
O presente artigo investiga a criminologia produzida pelos telejornais brasileiros, a chamada Criminologia Midiática, com enfoque nas discussões em torno do tráfico de drogas, delineando o conteúdo e a forma do discurso apresentado pelo programa Brasil Urgente, transmitido pela Rede Bandeirantes de Televisão. As edições do programa foram escolhidas de maneira aleatória entre os meses de setembro de 2017 e janeiro e março de 2018, para abarcar o máximo de variedade. Para o recorte específico foram escolhidas as matérias referentes a supostos delitos de tráfico de drogas, artigo 33 da Lei $n^{\circ}$ 11.343 de 2006. Dessa forma, foi possível perceber a formação de um contexto de "guerra", a partir construção da figura de inimigo acerca do traficante de drogas, signo este construído a partir dos ditos e não ditos no programa Brasil Urgente, de maneira a violar garantias fundamentais, como a presunção de inocência, espetacularizando o processo penal.
\end{abstract}

Palavras-chave: Criminologia midiática. Brasil Urgente. Tráfico de drogas. Direito Penal do Inimigo.

\section{INTRODUÇÃO}

A presente pesquisa parte da inquietação em torno da relação entre mídia e o fenômeno criminal no Brasil. Assim, o trabalho tem como ponto inicial a investigação de como os veículos midiáticos brasileiros retratam a questão criminal, o modo como seus discursos e suas diversas técnicas dá conta dessa matéria, quais resultados podem ser obtidos com essa forma discursiva e quais as consequências da disseminação reiterada de determinado discurso. Dessa forma, foi escolhido o programa "Brasil Urgente", televisionado nacionalmente pela Rede Bandeirantes de Televisão, como objeto de análise. 
O referido telejornal foi escolhido por tratar majoritariamente da matéria criminal em suas edições, bem como por sua presença de longa data na programação da TV brasileira. Assim, a pesquisa teve como metodologia a análise crítica do discurso observado na estrutura narrativa do programa, na tentativa de traçar as principais técnicas utilizadas pelo telejornal para a construção do discurso falado e não falado, de modo a investigar os ditos e não ditos pelo Brasil Urgente.

Como recorte específico para a leitura das amostras retiradas, foi escolhido o discurso em volta do delito de tráfico de drogas como o principal objeto de observação nas matérias coletadas. A escolha do referido tipo penal não foi à toa, o artigo 33 da Lei de Drogas (Lei $n^{\circ} 11.343$ de 2006) representa um dos crimes essenciais para a compreensão da realidade criminal do Brasil, especialmente por figurar como um dos tipos penais responsáveis pelas altas taxas de encarceramento no Brasil.

Assim, entendendo a política criminal de drogas como crucial para compreender a questão criminal brasileira, a relevância de estudos referentes ao tráfico de drogas fica devidamente demonstrada. A amostragem dos episódios do programa foi obtida de duas formas diferentes, mas ambas de maneira aleatória, buscando uma maior e melhor variedade de notícias a serem estudadas. A primeira foi a escolha de uma semana inteira de programas, que acabou sendo a última semana do mês de setembro de 2017. A segunda forma foi a escolha de um mês, onde seriam assistidos dois programas por semana. Os meses escolhidos foram janeiro, a metade de abril e a metade de maio, todos de 2018. Houve a transcrição do que foi dito pelos jornalistas do programa nas matérias, bem como foram registrados, de maneira descritiva, os cenários, posicionamentos das câmeras e dos apresentadores, cores, e volume das falas.

Dessa forma, especificamente para o delito tráfico de drogas, foi possível analisar os delineamentos próprios do indivíduo supostamente envolvido com tal delito, construídos pelos discursos verbalizados no programa. Ademais, de maneira geral, a narrativa acerca da investigação criminal em si também foi enfrentada, assim como a participação de especialistas ao vivo e como elas influenciam na compreensão do fato.

\section{O PARADIGMA QUESTIONÁ VEL DA POLÍTICA CRIMINAL DE DROGAS}

O presente tópico trata brevemente da política criminal de drogas utilizada no Brasil, através de um resumo histórico, bem como das atuais críticas e justificativas relacionadas ao 
objeto de análise empírica do trabalho. Como ponto de partida, tem-se que o termo "droga" pode ser definido na língua portuguesa como "denominação comum a todas as substâncias ou ingredientes usados em farmácia, química, tinturaria” (MICHAELIS, 2019), ou, nas palavras de Rosa Del Olmo (1990, p. 21): "na linguagem cotidiana, trata-se de toda substância capaz de alterar as condições psíquicas, e às vezes físicas, do ser humano, do qual, portanto, pode-se esperar qualquer coisa".

Assim, faz-se importante partir deste paradigma, pois nem todas as drogas são tidas como ilícitas, apesar de também provocarem efeitos psicoativos, ou seja, apenas é tida como ilícita a prática de algum, ou alguns, dos núcleos do tipo penal de tráfico no que diz respeito a determinadas drogas.

Para o presente trabalho, será feita apenas uma breve abordagem do histórico brasileiro no tocante ao tráfico de drogas, sabendo que a perseguição a certas substâncias psicoativas é um fenômeno histórico e mundial, cujos eventos possuem reflexos econômicos e sociais ${ }^{1}$. Entretanto, para um recorte mais preciso, foram delineadas as primeiras proibições brasileiras e o atual estado de controle penal das drogas. Determinado o recorte histórico, aponta-se, como o primeiro registro de proibição do uso e comercialização de drogas, o controle da maconha, através de lei da Câmara do Rio de Janeiro, publicada no dia 04 de outubro de 1830:

É proibida a venda e o uso do pito do pango, bem como a conservação dele em casas públicas. Os contraventores serão multados, a saber: o vendedor em $20 \$ 000$, e os escravos e mais pessoas, que dele usarem, em três dias de cadeia (HENMAN; PESSOA JUNIOR, 1986 apud BARROS, PERES, 2011, p. 8).

Assim, em que pese a criminalização do tráfico de drogas só surgir no Código Criminal de 1890 (CARVALHO, 1996, p. 24), a Câmara dos Vereadores do Rio de Janeiro já criminalizava, em 1830, o uso e a venda da cannabis sativa, também conhecida popularmente como "pito do pango", ou "maconha". Ressalte-se que essa previsão legal demonstra determinado nível de seletividade, inclusive racial, ao trazer que a pena para o usuário, à época, escravos ou demais pessoas, é restritiva de liberdade, enquanto que o vendedor seria apenado com multa. Sabe-se que, nesse momento da História, os vendedores de ervas e demais drogas eram os boticários, que receberiam pena pecuniária ao invés de ter sua

\footnotetext{
${ }^{1}$ Historicamente, aponta-se a chamada "Guerra do Ópio" como a primeira intervenção estatal organizada em face de uma droga. Ocorrido na China, o mencionado evento gerou a proibição do derivado da papoula, devido ao desequilíbrio econômico que ocorria da importação e consumo do ópio no interior do país. Contudo, a proibição do plantio acarretou em um descontrole comercial ainda maior, pois a importação continuou, beneficiando os países que vendiam o opioide para a China (VALOIS, 2017, p. 37).
} 
liberdade cerceada. Ou seja, há um mecanismo de seleção do tipo de pena para determinado sujeito, ocorrendo o que Baratta (2002, p. 166) vai chamar de "momento essencial para manutenção da escala vertical da sociedade".

Apesar dessa previsão da Câmara do Rio de Janeiro, em caráter nacional, a repressão aos entorpecentes no Brasil foi marcada por diversos tratados e leis, de 1890 até $1964^{2}$, sendo nítida a mudança de vertente política a partir do Golpe civil-militar, no qual o caráter de saúde pública dessa problemática, ainda que fosse tímido, deu espaço para uma dura repressão bélica.

O marco divisório entre o modelo sanitário e bélico (RODRIGUES, 2006, p. 142) ocorreu em 1964, quando o Brasil se inseriu de maneira amplamente bélica no contexto da política internacional de drogas, com a assinatura e recepção da Convenção Única sobre Entorpecentes, de 1961, promulgada pelo Decreto $\mathrm{n}^{\circ} 54.216^{3}$. Ressalte-se que a mencionada Convenção traz em seu preâmbulo um indisfarçável fundamento moral, e serviu de base para a estrutura das condutas tipificadas nas posteriores leis $\mathrm{n}^{\circ} 6.368$ de 1976 e $\mathrm{n}^{\circ} 11.343$ de 2006 (PRADO, 2013, p. 19-20).

Até então, em caráter nacional, as leis e os tratados recepcionados pelo Brasil não criminalizavam o usuário, e sim condutas que giravam entorno do uso, como venda, indução ao uso, posse sem receita médica, dentre outros, por entender que a dependência de drogas era uma questão de saúde que necessitava de tratamento médico. Entretanto, em 1968, no auge do regime militar, dias após do Ato Institucional n 5 ser outorgado (RODRIGUES, 2006, p. 144), houve alteração no artigo 281 do Código Penal, igualando o usuário ao traficante, ao determinar pena restritiva de liberdade de 01 a 05 anos, "contrariando toda orientação internacional e rompendo com o próprio discurso oficial fundamentado pela ideologia da diferenciação" (CARVALHO, 1996, p. 32). Ou seja, de fato, os anos 60 foram marcados por uma maior repressão aos entorpecentes, com aumento das penas pecuniárias e restritivas de liberdade e estabelecimento de tratamento igual entre o traficante e o usuário.

Nos anos 70, com uma abertura política trazendo novas possibilidades, a Lei $\mathrm{n}^{\circ} 6.386$ de 1976 revogou os artigos do Código Penal que tratavam da criminalização dos

\footnotetext{
${ }^{2}$ Dentre eles, a Convenção de Haia sobre o Ópio, de 1912; o Decreto n ${ }^{\circ} 4.294$ de 1921, que, pela primeira vez, a nível nacional, citou expressamente o ópio e a cocaína como substâncias criminalizadas; o Decreto ${ }^{\circ} 24.505$ de 1934, que elencou todos os entorpecentes ilícitos. Todos estes diplomas foram marcados pela forte influência dos médicos em sua redação, especialmente em condutas como "posse ilícita de entorpecentes sem receita médica", revelando o teor sanitarista.

${ }^{3}$ Pode-se dizer que a declaração de "guerra às drogas" a nível internacional se solidificou com a política norteamericana de "Lei e Ordem", que influenciou diretamente a política legislativa brasileira sobre o tema, principalmente quando as drogas saíram das periferias e invadiram a classe média, resultando na Convenção Única de Entorpecentes, de 1961 (CARVALHO, 1996, p. 27).
} 
entorpecentes, trazendo uma lei esparsa. À época, o controle penal das drogas ainda era consideravelmente severo, especialmente por ainda prever pena restritiva de liberdade para quem estivesse em posse de substâncias para consumo próprio. Entretanto, um paradigma que foi enfrentado pela nova lei foi o de determinar a política preventiva no combate aos entorpecentes. Ademais, a própria tipificação da posse para uso próprio, como um delito independente, foi considerada como um avanço no tipo de política a ser adotada, ainda que imponha pena ou internação (RODRIGUES, 1996, p. 151).

Atualmente, o controle penal das drogas é regulamentado pela Lei $\mathrm{n}^{\circ} 11.343$ de 2006, ainda como uma lei penal em branco, tendo em vista que não determina em seu rol quais as substâncias psicoativas que devem ser perseguidas criminalmente. Tal complemento normativo é feito pela Portaria $\mathrm{n}^{\circ} 344$ de 1998, atualizada pela Agência Nacional de Vigilância Sanitária (Anvisa). A lei representou, em certo aspecto, um avanço em relação ao conjunto normativo anterior, tendo em vista a diferenciação entre traficante e usuário, ao menos nas penas e no tratamento processual. Contudo, a ressalva é necessária, tendo em vista que a lei repete diversos verbos nas duas tipificações principais, quando traz, por exemplo, a simultaneidade das condutas "transportar, guardar, adquirir, trazer consigo".

Assim, tendo em vista a semelhança dos verbos, o que diferencia a tipificação é a destinação do entorpecente apreendido (PRADO, 2013, p. 55), sem que haja exigência de demonstração da finalidade econômica, mas existindo comprovação de que se destinava para uso. A interpretação da destinação do entorpecente é atribuída ao juiz, a partir dos critérios do artigo $28, \S 2^{\circ}$, da Lei $n^{\circ} 11.343$ de 2006, mas a referida técnica acabou por resultar em um aumento considerável da população carcerária condenada por tráfico de entorpecentes, sem provas mais vigorosas de seu envolvimento com o crime organizado (PRADO, 2013, p. 59).

Mesmo com todo o avançar da história, o número de encarcerados, ou sujeitos que já passaram pelo sistema carcerário de alguma maneira, tende apenas a aumentar, tendo o tráfico de drogas como um dos principais tipos encarceradores. Como aponta Valois (2017), o delito de tráfico de drogas possui um método de encarceramento relativamente simples, especialmente pela força da palavra do policial como produção de prova para a sentença condenatória, bem como a quantidade de prisões em flagrante feitas através e "atitudes suspeitas".

\section{A CRIMINOLOGIA PRODUZIDA PELOS MEIOS DE COMUNICAÇÃO}


Shecaira (2009, p. 38) coloca que a Criminologia pretende conhecer a realidade para explicá-la enquanto o Direito Penal valora, ordena e orienta a realidade, com o apoio de uma série de critérios axiológicos. Ou seja, a Criminologia seria um ramo das Ciências Criminais que desloca seu olhar para a compreensão da realidade criminal, abarcando os contextos, os sujeitos e as consequências da questão criminal. Nesse sentido, existem diversos ramos da Criminologia, desde a chamada Criminologia Tradicional, ou Positivista, até o ramo contemporâneo, mais radical, a chamada Criminologia Crítica, sendo equivocado afirmar que existe apenas uma Criminologia.

Dessa forma, a Criminologia é uma lente que encara a realidade criminal em seus reflexos, discursos e contextos. Assim, a Criminologia, em regra, é produzida pela academia em suas produções científicas, sejam teóricas ou empíricas. Partindo dessa premissa geral, Zaffaroni (2013) a problematiza, trazendo outros dois pontos de vista da Criminologia. Segundo o professor argentino, para tratar de realidade, de fato, a principal forma de compreensão da questão criminal seria a palavra dos mortos (ZAFFARONI, 2013, p. 8), através dos dados dos assassinados, que faz compreender a violenta política criminal utilizada especialmente pelos países latino-americanos. Entretanto, para o presente trabalho, a palavra da mídia tratada por Zaffaroni é a mais importante para se compreender.

Segundo o professor argentino, a mídia também é uma importante peça para compreensão da questão criminal, especialmente por produzir seu próprio saber em relação ao fenômeno penal, seus contextos e sujeitos. Assim, existe uma Criminologia Midiática, ou seja, uma tentativa dos meios de comunicação de compreender a realidade criminal, através de seus próprios métodos e técnicas. Nesse sentido, "a Criminologia Midiática sempre existiu e sempre apela a uma criação da realidade através de informação, subinformação e desinformação em convergência com preconceitos e crenças, baseada em uma etiologia criminal simplista, assentada na causalidade mágica” (ZAFFARONI, 2013, p. 194).

Importante ressaltar o conceito de causalidade mágica trazido por Zaffaroni, segundo o qual a mídia traz diversas respostas para a questão penal, que resolveriam rapidamente os problemas relativos ao crime, de maneira "mágica". Ressalte-se que o discurso veiculado pela mídia acaba eivado de punitivismo, como será demonstrado na análise empírica, e é referenciado por diversos "especialistas" na matéria, o que daria o respaldo científico ao que está sendo dito.

Dessa maneira, pode-se elencar como principais características da criminologia produzida pela mídia: a) a presença de especialistas a todo momento, que referenciam o que está sendo afirmado pelo programa; b) respostas rápidas, e praticamente mágicas, para 
resolução dos problemas relativos ao crime; c) discurso de fácil acesso para quem assiste, mas que apresenta dados e informações prontas, com certo nível de manipulação ideológica.

\section{INTERPRETAÇÃO CRÍtICA DE REPORTAGENS POLICIAIS DO "BRASIL URGENTE"}

A metodologia adotada para a realização desse trabalho foi a análise crítica do discurso, observando, através dessa lente, a não neutralidade do produtor do discurso e como ele produz um novo significado a partir das alterações da forma e da apresentação do conteúdo, por entender que o discurso é "um complexo processo de constituição desses sujeitos e produção de sentidos e não meramente uma transmissão de informação" (ORLANDI, 2015, p. 19).

Assim, foram assistidas diversas edições do programa "Brasil Urgente", sendo que a coleta dos dados foi feita ao vivo e com o recorte do delito de tráfico de drogas. Apesar da escolha do tipo penal, também foram assistidas algumas outras matérias, nas quais foi possível realizar certa dialética sobre as diferentes abordagens.

As principais características relativas à Criminologia Crítica foram elencadas nos subtópicos a seguir, que podem ser divididas entre: a) a presença de autoridades do sistema penal durante o programa; b) a espetacularização da investigação criminal; c) a violação de garantias fundamentais dos indivíduos investigados, que refletiram na identificação da criação de um estado de guerra, com a consequente construção de um inimigo.

\subsection{Autoridades do sistema criminal como atores do espetáculo}

Além do espetáculo proporcionado pelo discurso da mídia em si, presente nas técnicas do programa objeto da pesquisa, seja nas falas ditas, como nas silentes, sejam nas imagens repetidas diversas vezes ou nas dramatizações feitas pelos jornalistas, a Criminologia Midiática legitima seu conteúdo pela presença de autoridades técnicas, que estão a todo momento concordando e reforçando o que foi construído pelo telejornal. Ou seja, o que é afirmado pelo telejornal na cobertura da matéria passa por um crivo de confirmação de alguma autoridade judicial, policial ou política. 
$\mathrm{Na}$ amostra retirada, em diversos momentos, foi possível perceber a participação ao vivo de atores da persecução penal, que surgem como convidados do programa Brasil Urgente. A título de exemplo, durante a cobertura da chamada "Guerra na Rocinha", houve a participação ao vivo do então Ministro da Justiça, Torquato Jardim, explanando sobre as medidas que estavam sendo tomadas para contenção da situação vivida na comunidade da Rocinha.

Existem participações diárias dos delegados e agentes da polícia civil de São Paulo, explicando as operações atuais da polícia e como se dão as ações, bem como expondo opiniões sobre o atual cenário da questão criminal. Entretanto, o trecho a seguir foi escolhido para uma análise mais profunda, porque revela como o discurso criminológico midiático do programa se retroalimenta a partir da legitimação da fala policial, que surge como autoridade técnica do dia-a-dia da questão criminal.

\footnotetext{
[Urgente. Polícia apreende helicóptero do PCC]

Datena: - Quantos helicópteros ao todo? Esse Felipe é 'laranjão' do PCC. Isso ai não deve ser do cara, deve ser o próprio PCC, acho, mas deve ter muito mais. Se tem no nome desse cara, deve ter outros mais. Isso não me surpreende porque o promotor, Ministério Público de São Paulo de alta qualidade, disse que o PCC já cresceu tanto, que já deixou de ser uma facção, é um cartel. O Brasil é o segundo maior consumidor de cocaína do mundo, maior em crack. Então não me surpreende. (BRASIL URGENTE, 2018)

[Preso em flagrante. Segurança do tráfico armado em comunidade]

Datena: - O cara é preso de manhã e é solto pela audiência de custódia de tarde. A população, com esse sentimento de impunidade, busca o crime como solução. Já vi um caso de cara que procurou o Tribunal do Crime para apagar um cara que violentou a filha. A polícia resolve prender e a Justiça tem que deixar assim, correto ou 'tô' enganado?

Delegado do GARRA: - Corretíssimo, enquanto não tivermos leis pesadas e o bandido não tiver medo do devido processo penal. Isso é um problema legislativo, se ele souber que vai ficar preso 10 anos eu duvido que ele saia na comunidade armado, eu duvido, ele sabe que vai pra cadeia tomar café da manhã e vai pra rua. Datena: - O que protege a sociedade é lei, que garante a polícia e protege o cidadão, que 'tá' mais preso que o bandido que 'tá' na cadeia. Me 'dá' imagens das armas pesadas da polícia, porque se o bandido tem arma a polícia também tem. Como o povo acredita pouco na aplicação da lei. 'Ah não pode haver um linchamento judicial, coitadinho do bandido'. O juiz que tá próximo do que o povo pensa, mais próximo ele tá de uma decisão sábia, ele vai saber separar o que é clamor da população e o que é justiça de verdade [...] (BRASIL URGENTE, 2018).
}

Zaffaroni vai afirmar que faz parte do modo como a Criminologia Midiática atua se utilizar de falas de especialistas na matéria criminal, tendo em vista que não pode ignorar a necessidade de vestir-se como científica (ZAFFARONI, 2013, p. 149). O discurso seria disfarçado de científico, técnico, mas que no fundo é "mágico", visto que traz uma solução para todo o problema baseado no seu conhecimento do dia-a-dia, mas que nem sempre leva em consideração todos os fatores necessários. O que acaba por ocorrer é uma afirmação do 
que foi construído pelo programa, através da inversão ideológica sobre os fatos noticiados, que recebe o aval de legitimação pela fala da autoridade, apenas confirmando tudo que foi afirmado pelo próprio programa, mas agora com a força da palavra policial. O discurso da chamada "autoridade especialista" reforça o que é dito pelo programa, robustecendo o discurso por uma nova fala de autoridade (ZAFFARONI, 2013, p. 149).

O grande prejuízo reside no fato de que são autoridades que fazem parte do sistema judicial, que lidam diretamente com a matéria criminal, que acabam por legitimar, reforçar e refinar o discurso populista penal midiático do programa que entende por certo reduzir as garantias fundamentais dos indivíduos. A exemplo disso, tem-se a já citada afirmação de que a "audiência de custódia é um desserviço", sendo que este instituto já é previsto em tratado internacional assinado pelo Brasil, o Pacto de San Jose da Costa Rica, e apenas agora, após o sistema carcerário ser considerado como inconstitucional pelo Supremo Tribunal Federal (STF), através do julgamento da ADPF nº 347, conseguiu ser procedimentalizado. Inclusive, a afirmação de que as audiências de custódia são um desserviço é desacompanhada de dados empíricos, com suas respectivas fontes, o que reforça o teor de "mágica", nos dizeres de Zaffaroni, que possuem as soluções apresentadas pela mídia e reforçadas pelas autoridades especialistas.

\subsection{Espetacularização da persecução penal: quando o devido processo legal se torna parte do teatro}

O que se espera do Estado Democrático de Direito brasileiro, especialmente a partir da Constituição Federal de 1988, é que o processo penal seja eivado de princípios democráticos. Entre eles figura o devido processo legal, através do qual há paridade de armas entre as partes e imparcialidade na figura julgadora. Assim, o devido processo é uma garantia para que o procedimento possa legitimar o exercício da função jurisdicional. Nesse sentido, é imperioso ressaltar um trecho da clássica Teoria Geral do Processo, dos mestres Cintra, Grinover e Dinamarco:

Em conclusão, pode-se afirmar que a garantia do acesso à justiça, consagrando do plano constitucional o próprio direito de ação (como direito à prestação jurisdicional) e o direito de defesa (direito à adequada resistência às pretensões adversárias) tem como conteúdo o direito ao processo, como as garantias do devido processo legal. Por direito ao processo não se pode entender a simples ordenação de atos, através de um procedimento qualquer. O procedimento já de realizar-se em contraditório, cercando-se de todas as garantias necessárias para que as partes possam sustentar as razões, produzir provas, influir sobre a formação do 
convencimento do juiz. E mais: para que esse procedimento, garantido pelo devido processo legal, legitime o exercício da função jurisdicional (CINTRA; GRINOVER; DINAMARCO, 2009, p. 90).

Por outro lado, Duclerc vai além ao trazer o devido processo legal como um cânone do sistema processual acusatório, no qual as garantias de imparcialidade, contraditório e ampla defesa são plenamente protegidas (DUCLERC, 2016, p. 60). Dessa forma, o cenário que deve existir para a persecução penal é de garantias para que o acusado não sofra os excessos punitivos. Vale ressaltar que o sistema acusatório é um imperativo constitucional, a partir da Constituição Federal de 1988 (COUTINHO, 2014, p. 5).

E, sendo um sistema processual penal acusatório, as garantias fundamentais devem ser preservadas. Por outro lado, em um sistema inquisitorial, torna-se possível elucidar as fases processuais secretas, a possibilidade de o próprio juiz produzir provas, pouca ou nenhuma importância para o direito de defesa, ausência de contraditório e inversão da presunção de inocência (CARVALHO, 2015, p. 141). Inclusive, ressalte-se que, apesar do sistema inquisitorial ser demarcado pelo processo secreto, os suplícios, ou seja, o momento no qual o sujeito perseguido sofria mais, eram abertos ao público, como demonstra Michel Foucault em "Vigiar e Punir", ao tratar da execução de Damiens em praça pública (FOUCAULT, 1987, p. 8).

Em outras palavras, o que era importante, para o Poder Punitivo, ser exposto era feito de maneira aberta e incisiva, o que não era restava subterrâneo, sem o próprio acusado tomar conhecimento. Note-se que, na Criminologia Midiática atual, tudo é exposto de forma prejudicial ao acusado, inclusive a própria investigação, momento em que o investigado fica totalmente vulnerável. Tendo o sistema processual penal brasileiro o princípio acusatório como vertente principal, haja vista que não se pode mais falar em sistemas puros (COUTINHO, 2009, p. 109), a espetacularização do processo pela mídia, remetendo ao que Debord chamou de "sociedade do espetáculo", é algo incompatível com as garantias necessárias ao processo. Nas palavras de Rubens Casara:

\footnotetext{
O espetáculo, como percebeu Debord, 'não deseja chegar a nada que não seja ele mesmo'. A dimensão de garantia, inerente ao processo penal no Estado Democrático de Direito (marcado por limites ao exercício do poder), desaparece para ceder lugar à dimensão de entretenimento. (CASARA apud PRADO, 2015, p. 498).
}

Quando se tem em mente a importância do objeto do processo penal, que é a liberdade, todas as garantias vinculadas a ele se justificam além da seriedade da matéria. Ora, uma persecução penal aponta para a restrição da liberdade de alguém. Sendo assim, o 
processo penal precisa ser dotado daquilo que possa proteger o réu dos excessos punitivos. Dentro da persecução penal, tem-se uma dualidade entre a pretensão de liberdade de um lado e a pretensão punitiva do outro. Em suma, só se justifica a existência de um processo cercado de garantias e sujeito a um regime principiológico especialíssimo por causa da importância dos interesses que são objeto das pretensões penais, a liberdade e a punição (DUCLERC, 2016, p. 105).

Ou seja, a matéria criminal é evidentemente séria para não ser tratada como um "espetáculo", e existem sérios riscos ao se optar por isso. Casara identifica na sua lição como o processo penal se torna um entretenimento, tendo em vista o fascínio pelo crime e pelo endurecimento das penas (CASARA apud PRADO, 2015, p. 497). Indo além, não é apenas durante a fase processual propriamente dita que existe a espetacularização do processo penal, mas toda a persecução penal é alvo de interesse do entretenimento. Foi possível perceber nas amostras dos dias 25 e 26 de abril, por exemplo, a cobertura ao vivo da perícia técnica feita em um helicóptero apreendido pela polícia, que supostamente era utilizado pelo Primeiro Comando da Capital (PCC) para o tráfico de entorpecentes. Através da análise das referidas amostras, se pôde perceber que existe, de fato, um interesse de se apresentar ao público os mínimos detalhes do acontecimento, inclusive acompanhando o trabalho policial paripassu, com atualizações do que já foi descoberto:

\footnotetext{
[Urgente. Polícia apreende helicóptero do PCC]

Datena: - "Para você que chegou agora, esse helicóptero pertence ao PCC. Que prova, Joel? Os policiais acabaram de me dizer que tem resquícios de cocaína nesse helicóptero" (BRASIL URGENTE, 2018).

[Urgente. Polícia apreende helicóptero do PCC]

Datena: - "Agora pouco eu vi essa policial passando um pincel na porta para encontrar impressões digitais, para incriminar pessoas responsáveis por traficar drogas. Transportar traficantes e, principalmente, drogas. Veja o poderio dessas facções" (BRASIL URGENTE, 2018).
}

A persecução penal precisa ser eivada além da imparcialidade do juiz, mas também de autonomia no exercício das investigações. O Estado Democrático de Direito exige que as atividades judicial e policial sejam autônomas e democráticas, para que não sejam deturpadas. Inclusive, porque o discurso midiático do telejornal analisado é, a todo momento, afirmativo, tornando turva a linha que distingue uma fala isenta de opinião de uma acusação de culpa. $\mathrm{Ou}$ seja, o telejornal produz "mini-verdades", produzindo uma situação na qual a cada passo da polícia, durante a investigação, nasce uma afirmação diferente sobre a condição do suspeito alvo da persecução penal. 
Ainda que seja a fase investigativa, ela precisa de autonomia e instrumentalidade, tendo em vista que seu produto final, o inquérito, é o material probatório base para a acusação do Ministério Público. Nesse sentido, com base no Estado Democrático de Direito, o fim do inquérito policial deve ser o de servir ao processo penal, de modo a possibilitar um conhecimento maior acerca dos fatos e evitar acusações temerárias (DUCLERC, 2016, p 138), e não figurar como um espetáculo, no qual os refletores estão apontados para a perícia técnica enquanto o jornalista, que visa aumentar a audiência do programa, comenta paripassu como as leis deveriam ser mais rígidas, buscando, a todo tempo, o consenso dos telespectadores.

\subsection{Escolha de tratamentos: estado de inocência ou de "inimigo"?}

Entre as garantias fundamentais presentes no escopo constitucional, que perpassam diretamente a matéria criminal, tem-se o principal pilar de proteção ao indivíduo que é perseguido pelo processo penal: o estado de inocência, presente e fundamentado em tratados internacionais, como a Declaração Universal dos Direitos Humanos de 1948 e a Convenção Americana de Direitos Humanos de 1969, e na Constituição Federal da República, especialmente em seu artigo $5^{\circ}$, LVII.

Em outras palavras, todo Estado Democrático de Direito coloca a presunção de inocência como base da defesa do indivíduo processado no âmbito penal, exigindo que este seja considerado inocente até que as provas apuradas durante o processo demonstrem o contrário, afastando a necessidade do réu demonstrar sua não culpabilidade, visto que o ônus de apresentar tal situação é do Poder Punitivo (KARAM, 2009, p. 13). Dessa maneira, em um ordenamento jurídico que se diz democrático, o processo penal precisa ser baseado em um real estado de inocência, no qual tal presunção precisa existir tanto fora quanto dentro do processo penal.

Dessa forma, foi possível perceber, na amostra coletada, uma tendência do programa Brasil Urgente pelo desrespeito a essa garantia fundamental, através de um processo de rotulação dos sujeitos envolvidos nas matérias veiculadas. Tal fenômeno pôde ser percebido de maneira clara no discurso do Brasil Urgente, especialmente no recorte das matérias sobre tráfico de drogas. E, tendo em vista a observação das palavras escolhidas como adjetivo a ser utilizado, há uma forte ligação entre o processo de rotulação e a relativização de garantias fundamentais, em especial a presunção de inocência.

As adjetivações mais comuns dentre as escolhidas pelo Brasil Urgente para referir-se aos sujeitos julgados pelo programa foram "bandidos" e "vagabundos". Entende-se que esses 
adjetivos violam a presunção de inocência na medida em que eles ignoram a existência de um tratamento de inocência até que o processo demonstre o contrário pela apresentação das provas necessárias. A título de exemplificação, seguem alguns trechos retirados do referido telejornal no que diz respeito ao recorte do delito de tráfico de drogas:

\footnotetext{
[Urgente. Polícia apreende helicóptero do PCC]

Datena: - "Detalhe, o nome do cara é $\mathrm{F}(. ..) \mathrm{M}(. .$.$) . A moleza da legislação brasileira$ pra esses bandidos. Ela é muito mais leve pro bandido do que pro cidadão de bem, se o cara rouba um shampoo fica na cadeia. A lei favorece o bandido mais do que a gente imaginava. respondia em liberdade por um crime terrível que é o tráfico de drogas" (BRASIL URGENTE, 2018).

[Urgente. Polícia apreende helicóptero do PCC]

Datena: - "Esse 'mané' devia 'tá' no nome dele, mas deve ter sido comprado pelo PCC. Em que ponto chegou o crime organizado, enquanto em SP, estado mais rico, temos policial mal pago para correr heroicamente atrás de bandido, e a população brasileira também, não tem nada. E o PCC está com frota de helicóptero. Enquanto isso não for corrigido, esse país vai pro espaço" ( BRASIL URGENTE, 2018).

[Corpo de soldado encontrado. PM se jogou em rio para capturar traficante]

Datena: - "O bandido, de forma proposital, virou a canoa. O PM, infelizmente, foi levado pelas águas e o bandido também. Capaz de ter escapado o vagabundo. Ai morre o herói e o vagabundo fica vivo. Tomara que ele tenha morrido, esteja bem morto no inferno" (BRASIL URGENTE, 2018).
}

De maneira reflexa, esse tipo de violação também foi percebido pelo recorte ampliado da pesquisa feita pela Agência Nacional de Direitos da Infância (ANDI), em 2015, que produziu o Guia de Monitoramento das Violações, em dois volumes. De acordo com os jornalistas da ANDI, a violação do estado de inocência:

\footnotetext{
Ocorre quando um jornalista, radialista ou apresentador afirma que determinado indivíduo ou grupo de indivíduos cometeu um crime, tratando-o não como suspeito, mas como culpado, sem expor provas e sem que o indivíduo/grupo tenha sido julgado e condenado pelo suposto crime, desrespeitando preceito constitucional de presunção de inocência (VARJÃO, 2015, p. 15).
}

Nesse sentido, a construção de alguém como "bandido" ou "vagabundo", retira-lhe a condição de pessoa, atribuindo um adjetivo desumanizador. A partir do momento que a rotulação acontece, a representação daquele indivíduo aparece não somente como ser puramente perigoso, mas sua cidadania é negada e lhe é aferido o estigma de inimigo, ou nãopessoa (ZAFFARONI, 2014, p. 18). A partir do momento em que se declara alguém como inimigo, legitima-se qualquer medida que relativize suas garantias fundamentais. E, a partir do momento em que o indivíduo perde as garantias fundamentais, mais distante se torna a sua humanização, revelando mais um processo de retroalimentação do discurso midiático. 


\subsection{Produzindo o traficante como o inimigo}

Tem-se, por tudo o que fora fundamentado, que a mídia possui uma relação muito próxima com a questão criminal, produzindo o seu próprio discurso criminológico, com suas finalidades e técnicas. A partir disso, observa-se a contemplação da mídia como produtora de um discurso que fortalece o populismo penal, ávido por redução de garantias fundamentais e endurecimento das penas (GOMES; ALMEIDA, 2013, p. 27), e que produz uma série de rótulos para os sujeitos perseguidos criminalmente, que reduzem o estado de inocência.

Nesse sentido, cumpre destacar o papel da mídia como parte do sistema criminal, enquanto agência criminalizadora, que prepara o consenso em torno da necessidade de ampliação punitiva a partir da disseminação das notícias e da construção de um verdadeiro espetáculo do medo (GOMES; ALBUQUERQUE apud PINHO; DELUCHEY; GOMES, 2014, p. 81). E, enquanto produto da agência criminalizadora perpetrado pela mídia e inserido no sistema de Justiça Criminal, o discurso criminológico midiático ajuda a elencar quais são os casos que devem ser perseguidos com maior veemência, inclusive dedicando um maior tempo do seu horário de transmissão para tratar de determinado assunto. A partir desse processo de escolha e rotulação, a criminologia midiática realiza o processo de construção e desconstrução de determinadas imagens.

O que pode ser percebido, nesse sentido, é que as matérias relativas ao tráfico de drogas trazem consigo o reforço da declaração dos sujeitos como inimigos. No que se refere à amostragem coletada, tem-se a intitulada "Guerra na Rocinha", ocorrida no mês de setembro de 2017, marcada pela utilização das forças armadas pelo Governo Federal como forma de intervenção, anterior à intervenção militar propriamente dita ocorrida em janeiro de 2018. A forma como se intitula a matéria, com letras grandes, ocupando cerca de $30 \%$ da tela durante a reportagem, também indica o que o discurso do programa quer dizer sobre aquele fato. Partindo daí, o telejornal Brasil Urgente, por exemplo, escolheu por chamar o conflito ocorrido na zona sul do Rio de Janeiro de "guerra", assim como diversos outros meios midiáticos de massa. Por meio da rotulação do ocorrido como guerra, é possível fazer algumas considerações no sentido de se reconhecer cada vez mais, no discurso criminológico midiático do Brasil Urgente, a construção de inimigos. Em um ambiente de "guerra", diversas garantias individuais são relativizadas, e é criado um Estado de exceção. Note-se, pela própria Constituição Federal, que a única exceção da proibição da pena de morte é o período de 
guerras, vide o artigo $5^{\circ}$, XLVII, alínea "a", uma relativização do princípio da humanidade (BITENCOURT, 2015, p. 70).

Ou seja, o bem jurídico mais importante da Constituição Federal, a vida, é relativizada em casos de guerra. Nesse sentido, Zaffaroni afirma que, em ambientes de guerra, a limitação jurídica do poder Estatal é eximida, diferente do ambiente político, e que em nenhum momento esses dois podem se misturar (ZAFFARONI, 2014, p. 171).

Criar-se-ia, desse modo, um momento de "vale-tudo", já que, por conta da guerra, o controle judicial não existiria ou seria irrisório. Assim, dentro de um ambiente de guerra, seria uma consequência considerar alguém como inimigo, retirando-lhe a condição de pessoa e todas as garantias fundamentais que lhe são intrínsecas, legitimando o uso de qualquer medida hiperpunitiva.

Ao afirmar que um conflito complexo como o da Rocinha seria uma "guerra", o Brasil Urgente, assim como todos os veículos midiáticos de massa que assim o intitularam, apenas reforça a hostilidade contra o tráfico de drogas. Assim, abre-se um espaço de guerra, onde o limite judicial é fraco ou inexistente, os inimigos ali presentes deixam de ter qualquer garantia fundamental. Nesta senda, Jakobs vai afirmar que "um indivíduo que não admite ser obrigado a entrar em um estado de cidadania não pode participar dos benefícios do conceito de pessoa" (JAKOBS; MELIÁ, 2008, p. 35).

Gunther Jakobs, em sua obra "O Direito Penal do Inimigo", fundamenta e sustenta a possibilidade de coexistência entre dos direitos penais: o dos cidadãos e o dos inimigos, na qual as condutas dos primeiros deverão ser exteriorizadas para serem perseguidas, e as dos segundos devem ser interceptadas em estado prévio (JAKOBS; MELIÁ, 2008, p. 36). Entretanto, essa determinação de quem será o inimigo, no caso brasileiro, e, mais especificamente, na criminologia midiática manifesta no programa televisivo Brasil Urgente está eivada de uma seletividade social, e inclusive racial, vide os dados do INFOPEN Levantamento de informações penitenciárias (BRASIL, 2017) sobre o encarceramento de pessoas negras, especialmente pelo crime de tráfico de drogas, que figura como um dos crimes que mais encarcera no país. Nesse sentido, construir um discurso direcionado para um determinado "inimigo", a partir do delito de tráfico de drogas, faz com que se corra o risco de direcionar essa retirada de direitos a um público específico.

Não parece ser de interesse da mídia, enquanto agência criminalizadora, tendo em vista o que foi percebido, diminuir a força desse discurso, ao passo que apenas o replica e refina a cada nova "guerra". E, estando em um ambiente de "guerra", a rotulação do sujeito, 
onde lhe retiram o direito ao devido processo legal e ao estado de inocência, é justificada, tendo em vista que esse processo ocorre por ele ser considerado um inimigo.

Em detrimento do que considera Claus Roxin (2009, p. 61), cujo paradigma do Direito Penal como proteção ao bem jurídico é o que a dogmática eurocêntrica conseguiu de mais atual, entende-se que o sistema penal perde sua coerência, tendo em vista o seu caráter irracional que não consegue atingir os fins aos quais se pretende, próximo do que Tobias Barreto criticara como guerra, décadas atrás (BARRETO, 1926, p. 152-153). Assim, parte-se do marco teórico de que o papel do Direito Penal é o de contenção do avanço punitivo, segundo o qual a persecução penal deve ser vista como barreira que permita apenas a passagem do poder punitivo menos irracional, erguendo-se em barreira para o de maior irracionalidade (ZAFFARONI, 2014, p. 171).

A partir daí, a construção de um inimigo, através da qual se retira as garantias fundamentais por não considerar o suspeito como pessoa, é inaceitável em um Estado Democrático de Direito. E tal posicionamento não deve ser reforçado pelo conteúdo da criminologia midiática, sob pena de esta estar contribuindo para a corrosão dos parâmetros constitucionais, ao sugerir fundamentar e ilustrar a relativização das garantias constitucionais ou infraconstitucionais. De fato, a afirmação de Eugênio Raul Zaffaroni é extremamente acertada, a ponto de ser inteiramente transcrita pra cá, ao trazer o real inimigo do Estado Democrático de Direito:

O verdadeiro inimigo do direito penal é o Estado de polícia, que, por sua essência, não pode deixar de buscar o absolutismo. Neste embate de pulsões e contrapulsões não é possível ceder terreno algum, e menos ainda imaginar com ingenuidade que o inimigo se conformará com um hipotético espaço compartimentado, porque este não existe, dado que os limites são porosos, alternam-se de forma permanente e não são controláveis (ZAFFARONI, 2014, p. 175).

\section{CONSIDERAÇÕES FINAIS}

Por fim, cabe aqui pontuar as principais colocações do deslinde da pesquisa. Inicialmente, foi feito uma digressão histórica sobre a situação do controle penal das drogas no Brasil. Em ato contínuo, construiu-se a fundamentação teórica do que seria criminologia midiática, a fim de verificar se o discurso do Brasil Urgente faria parte dessa conceituação. A partir do recorte do crime de tráfico de drogas, optou-se por observar de que maneira o discurso do programa, nesses casos especificamente, relativiza garantias fundamentais. 
Percebeu-se que, de certa maneira, o programa Brasil Urgente reforça o caráter de "inimigo" mediante a rotulação do sujeito como "não pessoa", denominando como "guerra" o contexto em que se inserem indivíduos transgressões da lei penal, fazendo do conflito um ambiente que não possui qualquer garantia fundamental ou limitação judicial do poder punitivo.

Nesse sentido, afirma-se a criminologia midiática como "arauto" da guerra às drogas, remetendo a figura do arauto da Idade Média, que avisava a guerra com seus trompetes altos, bem como avisava quando os "inimigos" surgiam. Em outras palavras, sustenta-se, com essa pesquisa, que a criminologia produzida pelos meios de comunicação de massa contribui para a construção de um ambiente de "guerra", ao rotular pessoas suspeitas de crimes como um inimigo, o que identificou-se, na pesquisa, acontecer com suspeitos de tráfico de drogas, com a consequente relativização de suas garantias fundamentais.

O risco que se corre com esse "arauto" é a construção de um inimigo com viés seletivo, de modo a fortalecer uma necropolítica, por meio da qual a soberania ocorre a partir da escolha de quem vive e quem morre, relacionando o biopoder com um verdadeiro estado de sítio anunciado e fortalecido pela criminologia midiática. Nesta senda, o universo do espetáculo é o da ilusão, da aparência de acontecimento capaz de gerar sensações extraordinárias e hiperbólicas. É justamente nesse sentido que se apresentam as notícias referentes ao tráfico de drogas, disseminadas nos veículos da grande mídia: ocorre uma verdadeira fábrica de medo, na qual o estado de guerra é constantemente sustentado.

\section{REFERÊNCIAS}

ALBUQUERQUE, Fernando da Silva. GOMES, Marcus Alan de Melo. Mídia medo e expansão punitiva. In: PINHO, Ana Cláudia Bastos de. DELUCHEY, Jean-françois Y.. GOMES, Marcus Alan de Melo. Tensões contemporâneas da repressão criminal, 2014.

BARRETO, Tobias. Menores e loucos e fundamento do direito de punir. Maceió: Pongetti, 1926.

BARROS, André. PERES, Marta. Proibição da Maconha no Brasil e suas raízes históricas escravocratas. Revista Periferia, v.3, n. 2, Universidade Estadual do Rio de Janeiro. 
BITENCOURT, César Roberto. Tratado de Direito Penal: parte geral. v. 1. 21. ed. São Paulo: Saraiva, 2015.

BRASIL, Ministério da Justiça e Segurança Pública. INFOPEN - Levantamento nacional de informações penitenciárias. Junho de 2016. Brasília, 2017.

BRASIL URGENTE. Rede Bandeirantes. São Paulo. Episódio exibido no dia 08 de janeiro de 2018.

. Episódio exibido no dia 25 de abril de 2018

Episódio exibido no dia 26 de abril de 2018

CARVALHO, Salo de. Antimanual de Criminologia. 6. ed. São Paulo: Saraiva, 2015.

A politica criminal de drogas no Brasil:(do discurso oficial as razões da descriminalização). São Paulo: Saraiva Educação SA, 1996.

CASARA, Rubens. Processo Penal do Espetáculo. In: PRADO, Geraldo. Processo Penal e Garantias. Florianópolis: Empório do Direito, 2015. p. 497-500.

CINTRA, Antônio Carlos de. GRINOVER, Ada Pellegrini. DINAMARCO, Cândido Rangel. Teoria Geral do Processo. 25. ed. São Paulo: Malheiros, 2009.

COUTINHO, Jacinto Nelson de Miranda. Por que sustentar a democracia do sistema processual penal brasileiro? in. SEMINÁRIO DE DIREITO PENAL, CRIMINOLOGIA E PROCESSO PENAL EM HOMENAGEM A WINFRIED HASSEMER. Escola da Magistratura do Estado do Rio de Janeiro (EMERJ). Rio de Janeiro, 2014. Disponível em $<$ https://emporiododireito.com.br/leitura/por-que-sustentar-a-democracia-do-sistemaprocessual-penal-brasileiro>. Acesso em: 06 jun. 2019. Sistema acusatório Cada parte no lugar constitucionalmente demarcado. Revista de Informação Legislativa a. 43, e. 183. Senado Federal: Brasília, 2009.

DEL OLMO, Rosa. A face oculta da droga. Rio de Janeiro: Editora Revan, 1990. 
DUCLERC, Elmir. Introdução aos fundamentos do direito processual penal. Florianópolis: Editora Empório do Direito, 2017.

FOUCAULT, Michel. Vigiar e punir: nascimento da prisão. Tradução de Raquel Ramalhete. Petrópolis: Vozes, 1987.

GOMES, Flávio Luiz. ALMEIDA, Débora de Souza. Populismo Penal Midiático: caso mensalão, mídia disruptiva e direito penal crítico. São Paulo: Saraiva, 2013.

JAKOBS, Günther; MELIÁ, Manuel Cancio. Direito penal do inimigo. Rio de Janeiro: Lumen Juris, 2008..

KARAM, Maria Lúcia. Liberdade, Presunção de Inocência e Direito à Defesa. Rio de Janeiro: Lumen Juris, 2009.

MICHAELIS Moderno Dicionário da Língua Portuguesa. São Paulo: Editora Melhoramentos, 2015. Disponível em: <http://michaelis.uol.com.br/busca?r=0\&f=0\&t=0\&palavra=droga . Acesso em: 06 jun. 2019.

ORLANDI, Eni Pedro. Análise de Discurso: princípios e procedimentos. 12. ed. Campinas: Pontes Editores, 2015.

PRADO, Daniel Nicory do. Crítica ao controle penal das drogas ilícitas. 1 ed. Salvador: Editora Juspodium., 2013.

RODRIGUES, Luciana Figueiredo Bouteux. Controle penal sobre as drogas ilícitas: o impacto do proibicionismo no sistema penal e na sociedade. São Paulo: Universidade de São Paulo 2006

ROXIN, Claus. A proteção do bem jurídico como função do Direito Penal. 2. ed. Porto Alegre: Livraria do Advogado Editora, 2009.

SHECAIRA, Sérgio Salomão. Criminologia. São Paulo, Editora Revista dos Tribunais, 2009. 
VALOIS, Luis Carlos. O Direito Penal da guerra às drogas.2. ed. Belo Horizonte: Editora Plácido, 2017.

VARJÃO, Suzana. Violações de direitos na mídia brasileira: ferramenta prática para identificar violações de direitos no campo da comunicação de massa, ANDI, 2015, Vol. 1.

ZAFFARONI, Eugenio Raúl, A Questão Criminal. Tradução de Sérgio Lamarão. 1. ed. Rio de Janeiro: Revan, 2013.

O inimigo no Direito Penal. Tradução de Sérgio Lamarão. 3. ed. Rio de Janeiro:

Editora Revan, 2014.

THE MEDIA CRIMINOLOGY AS A DRUG WAR HERALD

\begin{abstract}
This article investigates the criminology produced by Brazilian newscasts, the so-called media criminology, focusing on discussions about drug trafficking, outlining the content and form of the discourse presented by the Brasil Urgente program, broadcast by Bandeirantes Television Network. The editions of the program were randomly chosen between September 2017 and January and March 2018, to encompass maximum variety. For the specific clipping were determined the matters related to alleged crimes of drug trafficking, article 33 of Law No. 11.343 of 2006. Thus, it was possible to perceive the formation of a context of "war", from the construction of the figure of an enemy around the drug dealer, a sign that was built from the said and unsaid in the Brasil Urgente program, in order to violate fundamental guarantees, such as the presumption of innocence, spectacularizing the criminal
\end{abstract}

Keywords: Drug trafficking. Media criminology. Enemy Criminal Law. 